\title{
Social media and ethics education
}

\author{
Henk ten Have ${ }^{1}$
}

Published online: 31 January 2019

(C) Springer Nature Switzerland AG 2019

Over the past few months, cities and roundabouts have been blocked in France by socalled yellow vest protesters. By law, every car should have a yellow vest in order to guarantee that the driver will be visible when there is an accident or breakdown. By showing the vest, ordinary citizens make themselves visible to governments and politicians that usually neglect their interests. The protests were not organized by established parties or trade unions; there were no leaders and no programs. It started with a posting on Facebook. All activities were coordinated online through "angry groups" with hundreds of thousands of members. The authorities were surprised and had no appropriate answers. This movement and many other examples demonstrate the power and significance of social media today.

In this issue Moses Kumi Asamoah analyses the advantages and disadvantages of social media, especially from an ethical point of view (Asamoah 2019). He correctly observes that there is a growing range of different types of social media. Writing a blog, watching a video on YouTube, contacting a friend via WhatsApp, or posting a message on FaceBook are heterogeneous activities. What they have in common is communication and connection. In distinction to more traditional media they have eliminated distance; we can easily connect with people everywhere on the globe; it is often irrelevant to know exactly where they are at the moment that we contact them. The new media are also much more interactive. While books, journals, radio and television provide information and aim at communication, it is usually one-way traffic while the new media allow dialogue and interaction. These distinctive characteristics potentially make social media an ideal forum and instrument for ethics teaching. Asamoah is well aware of the possible drawbacks of social media. They can be used to bring people together, criticize governments and organize protest but also instigate violence, promote discrimination, and launch hate campaigns. Through social media it is easier to express outrage and anger since the threshold for expressing is lower (Crockett 2017) Since there is not much chance of encountering the wrongdoer there is little risk of physical retaliation. The costs of shaming are lower although people's lives can be made difficult with online retaliations. Anger and moral outrage can be destructive; they can elicit a

Henk ten Have

henktenhave10@gmail.com

1 Duquesne University Center for Healthcare Ethics, Pittsburgh, PA, USA 
desire for revenge. They can lead to the perception that offenders are less than human ('monsters') and that they lack core human qualities (Bastian et al. 2013). Asamoah is particularly concerned with the dissemination via social media of false, embarrassing and "unclean" materials and information. He discusses how negative uses of the social media can be prevented. He rightly identifies the need for regulation. However, such regulation is highly controversial. One of the basic principles of internet is that it is free. At the same time, in many countries access and availability are restricted, not because social media disseminate unclean materials but since they criticize political regimes and emphasize human rights that are generally endorsed by the global community. It is not clear therefore that blocking internet access and censorship are based on ethical standards and media ethics, as Asamoah argues. Perhaps it should be, but the current practice is very different.

Nonetheless, the connection between social media and ethics education refers to a much more limited context. Rather than the uncritical anarchy that seems to reign in social media, ethics education seems to operate in a more specified and self-regulated environment. Not everybody can make contributions. Teaching programs and courses require a significant effort. One can make a video about a specific ethical problem but if the quality is low it will not be used in teaching programs (or as a bad example). The same for 'lectures' and presentations; they can be posted but whether they will be used for educational purposes is a different matter. Therefore, the fact that numerous materials are available, does not imply that they will be regarded and used as educational materials. That decision is made by professionals who will apply certain quality standards.

In conclusion: the use of social media in various teaching contexts is specific. Ethics education can benefit from the advantages offered by these media: rapid and easy communication, sharing of experiences and ideas, and dialogue and interaction. This is especially clear in the rapidly growing number of online ethics teaching programs. More students than ever can be reached by such programs. That does not mean that the trend to replace face-to-face classes in ethics by online courses is not raising serious questions about the role and impact of ethics teaching. Social media also facilitate the dialogue and interactions between students and teachers. Finally, these media present an astonishing range of materials that might be useful for teaching. Many resources such as books and journal articles are now accessible for free. The number of videos about bioethical problems is amazing. With the emergence of global bioethics as a broader, more compassing approach to bioethical problems this is a positive development since it offers ethics professionals opportunities to make their teaching more diverse and reflective.

Publisher's note Springer Nature remains neutral with regard to jurisdictional claims in published maps and institutional affiliations.

\section{References}

Asamoah, Moses Kumi. 2019. The two side coin of the online social media. Eradicating the negatives and augmenting the positives. International Journal of Ethics Education 4(1): 1-19.

Bastian, Brock, Thomas F. Denson, and Nick Haslam. 2013. The roles of dehumanization and moral outrage in retributive justice. PLoS One 8 (4): e61841. https://doi.org/10.1371/journal.pone.0061842.

Crockett, M.J. 2017. Moral outrage in the digital age. Nature Human Behavior 1: 769-771. 